\title{
Emergence of multidrug-resistant non-fermentative gram negative bacterial infection in hospitalized patients in a tertiary care center of Nepal
}

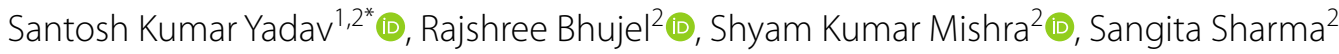
and Jeevan Bahadur Sherchand ${ }^{2}$

\begin{abstract}
Objective: This study was designed for the characterization and establishment of antibiotic susceptibility profiles of non-fermentative gram negative bacteria isolated from hospitalized patients in a tertiary care hospital of Nepal.

Results: A total of 402 non-fermentative gram negative bacteria was isolated in 1486 culture-positive cases from 6216 different clinical samples obtained from hospitalized patients. Among total non-fermentative gram negative bacterial isolates, the highest number was recovered from specimens collected from lower respiratory tract infections ( $n=173,43.0 \%$ ) of hospitalized patients followed by pus/swab samples $(n=99,24.6 \%)$ and urinary tract infections $(n=49,12.2 \%)$. The most common non-fermentative gram negative bacteria identified were Acinetobacter baumannii $(n=177,44.0 \%)$, Pseudomonas aeruginosa $(n=161,40.1 \%)$ and Burkholderia cepacia complex $(n=33,8.2 \%)$. These bacterial isolates exhibited a higher rate of insusceptibility to beta-lactam antibiotics, fluoroquinolones, and aminoglycosides. On the other hand, all the isolates of P. aeruginosa and A. baumannii were completely susceptible to colistin sulfate and polymyxin B. Among total isolates, $78.1 \%(n=314)$ were multidrug-resistant with a high rate of multidrugresistant among A. baumannii (91.0\%).
\end{abstract}

Keywords: Acinetobacter baumannii, Hospitalized patients, Multidrug-resistant, Non-fermentative gram negative bacteria, Pseudomonas aeruginosa

\section{Introduction}

Non-fermentative gram negative bacteria (NFGNB) are a heterogeneous group of bacteria that includes Pseudomonas species, Acinetobacter species, Burkholderia species, Stenotrophomonas maltophilia, etc. These organisms are omnipresent and may be recovered from various hospital instruments as well as from the body surface of healthcare workers [1]. They can cause a vast variety

\footnotetext{
*Correspondence: santooshydv@gmail.com

1 Department of Microbiology, Rajarshi Janak University, Janakpurdham, Nepal

Full list of author information is available at the end of the article
}

of infections in hospitalized patients and account for approximately $15 \%$ of all gram negative bacterial infections [2]. NFGNB pose significant challenges in health care settings because of their multiple, intrinsic, or acquired antibiotic resistance. The burden of resistance is presumably more due to the higher rate of empirical antimicrobial treatment than with the virulence of particular strains [3]. NFGNB are becoming a threat to health care systems because these bacteria are mainly associated with opportunistic infections in critically ill and immunocompromised patients. The emergence of infections by these organisms along with the rising drug resistance among them warrants close monitoring of the

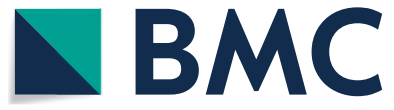

(c) The Author(s) 2020. This article is licensed under a Creative Commons Attribution 4.0 International License, which permits use, sharing, adaptation, distribution and reproduction in any medium or format, as long as you give appropriate credit to the original author(s) and the source, provide a link to the Creative Commons licence, and indicate if changes were made. The images or other third party material in this article are included in the article's Creative Commons licence, unless indicated otherwise in a credit line to the material. If material is not included in the article's Creative Commons licence and your intended use is not permitted by statutory regulation or exceeds the permitted use, you will need to obtain permission directly from the copyright holder. To view a copy of this licence, visit http://creativeco mmons.org/licenses/by/4.0/. The Creative Commons Public Domain Dedication waiver (http://creativecommons.org/publicdomain/ zero/1.0/) applies to the data made available in this article, unless otherwise stated in a credit line to the data. 
antimicrobial susceptibility profile of these organisms [4]. The objective of this study was to characterize NFGNB and determine its antibiotic susceptibility among hospitalized patients.

\section{Main text \\ Methods}

This study was conducted at the department of clinical microbiology of Tribhuvan University Teaching Hospital, Nepal from January 2017 to December 2017. The various specimens collected from hospitalized patients (suspected with infections) were processed for isolation and identification of NFGNB. The lower respiratory tract specimens and body fluid samples were inoculated on chocolate agar (CA) plate, $5 \%$ sheep blood agar (BA) plate, and MacConkey agar (MA) plate. Blood samples were initially enriched with Brain Heart Infusion Broth (BHIB) and then subcultured on to the BA and MA plates. Similarly, wound swab, pus, catheter tips, and urine samples were cultured on BA and MA plates. The $\mathrm{CA}$ plates were incubated in $\mathrm{CO}_{2}$ incubator at $37^{\circ} \mathrm{C}$ for $24 \mathrm{~h}$. The BA and MA plates were incubated at $37^{\circ} \mathrm{C}$ for $24 \mathrm{~h}$ in an aerobic condition [5]. The identification of significant NFGNB isolates that are associated with infections was performed following standard microbiological techniques which involved the morphological appearance of the colonies, Gram's staining, motility test and a battery of biochemical tests which included oxidase test, sugar fermentation test including triple sugar iron agar, citrate and acetamide utilization test, nitrate reduction test, decarboxylation tests, gelatin liquefaction test, deoxyribonuclease test, etc [6].

The susceptibility of bacterial isolates against different antibiotics was determined by the Kirby-Bauer disk diffusion method and minimum inhibitory concentration
(MIC) method for some antibiotics. Interpretations of antibiotic susceptibility test results were made according to the guidelines provided by the Clinical and Laboratory Standards Institute (CLSI) (26th Edition) [7]. Escherichia coli ATCC 25922 and P. aeruginosa ATCC 27853 were used as the control organisms for the antibiotic sensitivity test. The isolates resistant to at least one antibiotic in three or more antimicrobial classes were confirmed as multidrug-resistant (MDR) phenotype $[5,8]$.

The data generated during the study were analyzed by using the SPSS version 16.0 and interpreted according to frequency distribution and percentage.

\section{Results}

From a total of 6216 specimens, 1486 (23.9\%) showed significant bacterial growth which included 402 NFGNB (27.1\% of culture-positive). The isolation rate of NFGNB was highest from lower respiratory tract infection (37.2\%) and lowest from urinary tract infection (17.5\%). Among the total of 402 NFGNB isolates, $58.5 \%(\mathrm{n}=235)$ were isolated from male and $41.5 \%(n=167)$ were from female patients, with male to female ratio 1.41 . The highest number of isolates were from the age group $16-32$ years $(n=100)$ and the least number from the age group 49-64 years $(n=66)$.

From total isolates, nine species of NFGNB were identified which included Acinetobacter baumannii ( $\mathrm{n}=177$, $44.0 \%)$ followed by Pseudomonas aeruginosa $(\mathrm{n}=161$, 40.1\%), Burkholderia cepacia complex ( $\mathrm{n}=33,8.2 \%), A$. calcoaceticus ( $\mathrm{n}=11,2.7 \%)$, A. lwoffii $(\mathrm{n}=10,2.5 \%)$, and few other isolates. The majority of $A$. baumannii $(\mathrm{n}=82)$ and Pseudomonas aeruginosa $(\mathrm{n}=79)$ were recovered from lower respiratory tract specimens i.e. sputum, bronchoalveolar lavage, and endotracheal aspirates (Table 1). Among wards, 39.1\% of total NFGNB were isolated from

Table 1 Distribution of non-fermentative gram negative bacteria in different clinical specimens

\begin{tabular}{|c|c|c|c|c|c|c|c|}
\hline \multirow[t]{2}{*}{ NFGNB isolates } & \multicolumn{7}{|c|}{ Clinical specimens } \\
\hline & LRTS $^{a}$ & Pus/swabs & Urine & Body fluids & Blood & Catheter tips & Total number (\%) \\
\hline Acinetobacter baumannii & 82 & 49 & 13 & 20 & 10 & 3 & $177(44.0)$ \\
\hline Acinetobacter calcoaceticus & 2 & 3 & 3 & 2 & 1 & - & $11(2.7)$ \\
\hline Acinetobacter Iwoffii & - & 6 & 2 & 2 & - & - & $10(2.5)$ \\
\hline Acinetobacter haemolyticus & - & - & 3 & - & - & - & $3(0.8)$ \\
\hline Pseudomonas aeruginosa & 79 & 37 & 21 & 18 & 4 & 2 & $161(40.1)$ \\
\hline Pseudomonas stutzeri & - & 1 & - & - & 1 & - & $2(0.5)$ \\
\hline Burkholderia cepacia complex & 8 & 2 & 7 & 5 & 9 & 2 & $33(8.2)$ \\
\hline Stenotrophomonas maltophilia & 1 & 1 & - & 1 & 1 & - & $4(1.0)$ \\
\hline Sphingobacterium species & 1 & - & - & - & - & - & $1(0.2)$ \\
\hline Total number (\%) & $173(43.0)$ & $99(24.6)$ & $49(12.2)$ & $48(12.0)$ & $26(6.5)$ & $7(1.7)$ & $402(100)$ \\
\hline
\end{tabular}

a Lower respiratory tract specimens include sputum, bronchoalveolar lavage, and endotracheal aspirate 
intensive care unit (ICU) patients, an equal number (21.9\%) from each surgical and medical wards followed by orthopedics $(6.5 \%)$, pediatrics $(4.9 \%)$, maternity $(4.2 \%)$ and burn ward (1.5\%).

Acinetobacter baumannii and Pseudomonas aeruginosa showed a low level of sensitivity to most of the commonly tested antibiotics in clinical practice. When results were critically analyzed for the common organisms amongst these we found that $A$. baumannii and $P$. aeruginosa showed resistance to most of the common drugs except polymyxin B and colistin sulfate. Acinetobacter calcoaceticus, A. lwoffi, A. haemolyticus, and $P$. stutzeri showed high sensitivity against the tested antimicrobials. All the isolates of Burkholderia cepacia complex and Stenotrophomonas maltophilia showed a considerable amount of sensitivity to co-trimoxazole and doxycycline (Table 2). Among total NFGNB isolates, $78.1 \%$ were MDR with a high rate among $A$. baumannii. P. aeruginosa and B. cepacia complex (Table 3).

\section{Discussion}

Infection in hospitalized patients is a global health problem. Despite awareness and hospital care, infections continue to develop in hospitalized patients [9]. Nonfermentative gram negative bacteria were previously considered less significant pathogens but they have now
Table 3 Multidrug resistance rate in non-fermentative gram negative bacterial isolates

\begin{tabular}{lcl}
\hline NFGNB isolates (number of isolates) & \multicolumn{2}{l}{ MDR in NFGNB } \\
\cline { 2 - 3 } & Number & Percentage \\
\hline Acinetobacter baumannii $(\mathrm{n}=177)$ & 161 & 91.0 \\
Acinetobacter calcoaceticus $(\mathrm{n}=11)$ & 4 & 36.4 \\
Acinetobacter /woffii $(\mathrm{n}=10)$ & 0 & 0 \\
Acinetobacter haemolyticus $(=3)$ & 0 & 0 \\
Pseudomonas aeruginosa $(\mathrm{n}=161)$ & 118 & 73.3 \\
Pseudomonas stutzeri $(\mathrm{n}=2)$ & 0 & 0 \\
Burkholderia cepacia complex $(\mathrm{n}=33)$ & 26 & 78.8 \\
Stenotrophomonas maltophilia $(\mathrm{n}=4)$ & 4 & 100 \\
Sphingobacterium species $(n=1)$ & 1 & 100 \\
Total (N=402) & 314 & 78.1 \\
\hline
\end{tabular}

emerged as important nosocomial pathogens [10]. In our study, a total of 402 NFGNB were isolated from hospitalized patients which are $27.1 \%$ of culture-positive samples. A similar growth rate of NFGNB was documented by Bhagava et al. (29.6\%) [11] from Nepal and Sharma et al. (25.6\%) [9] from India while Rahbar et al. [12] reported a positivity rate of only $15 \%$ for NFGNB from Iran. These variations in the prevalence of NFGNB in different health

Table 2 Antibiotic susceptibility profile of non-fermentative gram negative bacterial isolates

\begin{tabular}{|c|c|c|c|}
\hline \multirow[t]{2}{*}{ Antibiotics } & \multicolumn{3}{|c|}{ Sensitivity rate of non-fermentative gram negative bacteria (\%) } \\
\hline & Acinetobacter baumannii $(n=177)$ & Pseudomonas aeruginosa $(n=161)$ & $\begin{array}{l}\text { Burkholderia } \\
\text { cepacia complex } \\
(n=33)\end{array}$ \\
\hline Ampicillin-sulbactam & 18.6 & NT & NT \\
\hline Piperacillin & 6.2 & 21.7 & NT \\
\hline Piperacillin-tazobactam & 12.4 & 38.5 & NT \\
\hline Ceftazidime & 6.2 & 13.0 & 12.1 \\
\hline Cefotaxime & 4.5 & NT & NT \\
\hline Cefepime & 6.8 & 15.5 & NT \\
\hline Meropenem & 18.1 & 38.5 & 66.7 \\
\hline Imipenem & 20.3 & 42.2 & NT \\
\hline Ciprofloxacin & 11.3 & 12.4 & NT \\
\hline Ofloxacin & NT & 13.7 & NT \\
\hline Levofloxacin & 19.2 & 23.0 & 15.2 \\
\hline Gentamicin & 14.1 & 43.5 & NT \\
\hline Amikacin & 20.9 & 62.7 & NT \\
\hline Co-trimoxazole & 4.0 & NT & 100 \\
\hline Doxycycline & 42.9 & NT & 72.7 \\
\hline Polymyxin B & 100 & 100 & NT \\
\hline Colistin sulfate & 100 & 100 & NT \\
\hline Chloramphenicol & NT & NT & 45.5 \\
\hline
\end{tabular}

NT antibiotics not tested/not recommended by CLSI 
care settings might be due to the infection control practices and circulation of these bacterial pathogens in respective hospitals. The demographic data in our study showed patients most commonly affected by NFGNB infections were male and between age 16-32 years, which is in accordance with the study done by Benachinmardi et al. [13]. In this study, the incidence of infections with NFGNB was found to be highest from lower respiratory tract specimens $(43.0 \%)$, followed by pus and swabs (24.6\%), urine (12.2\%), body fluids (12.0\%) and blood (6.5\%). Nautiyal et al. [14] from India also reported major NFGNB isolates from lower respiratory tract specimens (42.3\%) followed by pus samples $(28.6 \%)$ while Bhatnagar et al. [15] reported most of the NFGNB isolates from pus samples (49.2\%) and the next common being sputum sample (19.8\%).

Among total isolates, $A$. baumannii was the most common isolates (44.0\%) followed by P. aeruginosa (40.1\%), B. cepacia complex (8.2\%), and A. calcoaceticus (2.7\%). Parajuli et al. [5] and Sah et al. [16] also reported A. baumannii as the major NFGNB isolates from hospitalized patients. Acinetobacter baumannii and P. aeruginosa were the most frequently isolated from lower respiratory tract specimens, pus, and urine samples. This result is supported by other studies [10, 17]. Acinetobacter species is an important nosocomial pathogen imposing greater problem to the management of hospitalized patients and infection control [18]. Samawi et al. [19] from Qatar also reported major A. baumannii from respiratory tract infection. Other Acinetobacter species were commonly isolated from pus and swab samples. In this study, $P$. aeruginosa was the second commonest NFGNB accounting for $40.1 \%$ of total isolates. Other studies from Nepal $[20]$ and India $[9,21]$ also revealed a high prevalence of $P$. aeruginosa from respiratory tract infections. Parajuli et al. [5] reported most of the P. aeruginosa from VAP, followed by SSI and UTI of ICU patients. In recent years Burkholderia cepacia complex has emerged as an important nosocomial pathogen and its multidrug resistance makes its presence dangerous in hospital settings. In our study, most of the B. cepacia complex was associated with bloodstream infection $(\mathrm{n}=9,27.3 \%)$. Dizbay et al. [22] from Turkey also reported $25.6 \%$ B. cepacia complex from bloodstream infection. Stenotrophomonas maltophilia infections are acquiring increasing importance in the hospital environment. In this study, A total of four S. maltophilia were isolated, one from each blood, sputum, body fluid, and pus sample. Sphingobacterium species $(n=1)$ was isolated from the sputum sample of a patient with pneumonia. There are certain reported cases of bacteremia, respiratory tract infection, and meningitis due to Sphingobacterium species from various countries $[23,24]$.
The pattern of NFGNB infections among patients of different wards was evaluated in this study. High prevalence of NFGNB was isolated from patients of intensive care units (39.1\%) followed by surgical and medical wards (21.1\% each), orthopedic (6.5\%), and pediatric (4.9\%) wards. Other studies $[25,26]$ have also reported a higher incidence of NFGNB infection in ICU patients. It is a well-known fact that the infection rates in ICUs are many times higher than elsewhere in hospitals as ICUs are the hub of critically ill patients, who are most vulnerable to opportunistic infections by NFGNB. In our study, the most common NFGNB causing infections in ICU patients were $A$. baumannii $(\mathrm{n}=84,53.5 \%)$ followed by $P$. aeruginosa $(\mathrm{n}=55,35.0 \%)$ and $B$. cepacia complex $(\mathrm{n}=15,9.6 \%)$. Acinetobacter spp. as the commonest NFGNB pathogen in ICU patients was also documented by Parajuli et al. [5] and Mishra et al. [27].

This study showed lower susceptibility of different NFGNB against many antimicrobials with a high multidrug resistance rate. As a consequence of easy access and haphazard use, many antibiotics have decreased their effectiveness in Nepal. Acinetobacter baumannii isolates showed a very low sensitivity rate $(<25 \%)$ against penicillins, cephalosporins, fluoroquinolones, aminoglycosides, and even carbapenems. They were moderately and highly susceptible to doxycycline (42.9\%) and polymyxins $(100 \%)$, respectively. The resistance rate is higher than the previous results from the same hospital [28]. Parajuli et al. [5] and Shrestha et al. [18] reported similar antibiotic susceptibility profiles among A. baumannii. Xia et al. [29] documented only $15 \%$ A. baumannii susceptible to carbapenems. On the other hand, A. calcoaceticus, $A$. lwoffii, and A. haemolytics were found highly susceptible to common antimicrobials. Pseudomonas aeruginosa isolates were also found to be highly resistant against $\beta$-lactams. Among different antibiotics tested, only 13.0\% isolates were found to be susceptible to ceftazidime, $15.5 \%$ to cefepime, $38.5 \%$ to meropenem, $42.2 \%$ to imipenem, $12.4 \%$ to ciprofloxacin and $23.0 \%$ to levofloxacin, while all the isolates were completely susceptible to polymyxin B and colistin sulfate. Fatima et al. [30] and Xie et al. [29] reported a lower resistance rate in $P$. aeruginosa against beta-lactam antibiotics. Our finding well correlates with the observations of other studies [5, 31, 32]. All the isolates of B. cepacia complex were found susceptible to co-trimoxazole, $72.7 \%$ to doxycycline, $66.7 \%$ to meropenem, and only $12.1 \%$ to ceftazidime. A similar pattern of susceptibility was reported by Parajuli et al. [5] among ICU patients.

The MDR rate among A. baumannii was $91.0 \%$ which is extensively high. Shrestha et al. [33] and Mishra et al. [28] also reported around 96\% and 95\% MDR A. baumannii, respectively. We found $73.3 \%$ MDR 
P. aeruginosa isolates which are higher than those reported by Mishra et al. [34] from Nepal in 2008 (65.9\%), Prakash et al. [35] from India in 2014 (31.7\%), and Hassuna et al. [36] from Egypt in 2015 (56\%). The rate of MDR $P$. aeruginosa is in an upward trend throughout the world especially in developing countries causing a life-threatening situation. Stenotrophomonas maltophilia is intrinsically resistant to many antibiotics and MDR is common. In this study, all the S. maltophilia was found to be MDR and only $25.0 \%$ isolates were susceptible to levofloxacin and chloramphenicol and $50.0 \%$ to doxycycline. Sattler et al. [37] reported a similar resistance rate among $S$. maltophilia.

In this study, polymyxin B and colistin sulfate showed excellent effect against Acinetobacter species and $P$. aeruginosa isolates. Co-trimoxazole was found effective against B. cepacia complex and S. maltophilia. The antibiotic resistance among these bacteria has dramatically increased in the last decades and pose a significant challenge to effective therapeutic strategies. Menacing a state of low antimicrobial susceptibility among NFGNB associated with these infections is particularly worrisome. Therefore, surveillance of antibiotic susceptibility profiles of these bacteria should be regularly done.

\section{Limitations}

We were unable to evaluate the risk factors and outcomes of NFGNB infections in hospitalized patients due to the unavailability of sufficient data. Furthermore, molecular analysis of the resistant phenotypes and genetic mechanism of drug resistance was not determined.

\section{Supplementary information}

Supplementary information accompanies this paper at https://doi. org/10.1186/s13104-020-05163-6.

Additional file 1: Table S1. Distribution of specimens and growth rate of non-fermentative gram negative bacteria. Table S2. Distribution of nonfermentative gram negative bacteria with the demographic features of patients. Table S3. Ward wise distribution of non-fermentative gram negative bacterial isolates.

\section{Abbreviations}

AST: Antibiotic susceptibility testing; ATCC: American type culture collection; BA: Blood agar; BHIB: Brain Heart Infusion Broth; CA: Chocolate agar; CLSI: Clinical and Laboratory Standards Institute; ICU: Intensive care unit; LRTS: Lower respiratory tract specimens; MA: MacConkey agar; MDR: Multidrug-resistant; MIC: Minimum inhibitory concentration; NFGNB: Non-fermentative gram negative bacteria; SPSS: Statistical Package for Social Sciences; SSI: Surgical-site infection; UTI: Urinary tract infection; VAP: Ventilator-Associated Pneumonia.

\section{Acknowledgements}

Authors would like to express their sincere gratitude to all the faculties of the Department of Clinical Microbiology and staff of different wards of Tribhuvan University Teaching Hospital, Nepal for their generous support throughout this study.
Authors' contributions

SKY: Conceptualization, investigations, statistical analysis, writing an original draft and final version of the manuscript; RB: Conceptualization, investigations, writing-review, and editing; SKM, SS, JBS: Conceptualization, investigations, supervision, writing-review, and editing. All authors read and approved the final manuscript.

\section{Funding}

This work was conducted with partial financial assistance from the Nepal Health Research Council (NHRC) (No. 773).

\section{Availability of data and materials}

All data generated or analyzed during this study are included in this published article and its additional information files (Additional file 1:Table S1-S3).

\section{Ethics approval and consent to participate}

The ethical approval for the study was obtained from the Institutional Review Board of the Institute of Medicine, Kathmandu, Nepal (Ref. No. 262). Written informed consent was obtained from each patient before enrollment and where participants are children (under 16 years old) from their parent or guardian.

\section{Consent for publication}

Not applicable.

\section{Competing interests}

The authors declare that they have no competing interests.

\section{Author details}

${ }^{1}$ Department of Microbiology, Rajarshi Janak University, Janakpurdham, Nepal. ${ }^{2}$ Department of Clinical Microbiology, Institute of Medicine, Tribhuvan University Teaching Hospital, Kathmandu, Nepal.

Received: 17 March 2020 Accepted: 27 June 2020

Published online: 02 July 2020

\section{References}

1. Mellmann A, Bimet F, Bizet C, Borovskaya A, Drake R, Eigner U, et al. High interlaboratory reproducibility of matrix-assisted laser desorption ionization-time of flight mass spectrometry-based species identification of nonfermenting bacteria. J Clin Microbiol. 2009;47:3732-4. https://doi. org/10.1128/JCM.00921-09.

2. Siou C, Vaneechoutte M, Dijkshoorn L, Wei Y, Chen Y, Chang T. Identification of non-fermenting Gram-negative bacteria of clinical importance by an oligonucleotide array. J Med Microbiol. 2009;58:596-605. https://doi. org/10.1099/jmm.0.004606-0.

3. Costa S. Impact of antimicrobial resistance on the treatment and outcome of patients with sepsis. Shock. 2008;30:23-9. https://doi. org/10.1097/SHK.0b013e3181818990.

4. Gautam V, Kumar S, Kaur P, DeepakT, Singhal L, Tewari R, et al. Antimicrobial susceptibility pattern of Burkholderia cepacia complex \& Stenotrophomonas maltophilia over six years (2007-2012). Indian J Med Res. 2015;142:492-4. https://doi.org/10.4103/0971-5916.169225.

5. Parajuli NP, Acharya SP, Mishra SK, Parajuli K, Rijal BP, Pokhrel BM. High burden of antimicrobial resistance among gram negative bacteria causing healthcare associated infections in a critical care unit of Nepal. Antimicrob Resist Infect Control. 2017;6:67. https://doi.org/10.1186/s1375 6-017-0222-z.

6. Isenberg H. Clinical microbiology procedure handbook. 2nd ed. Washington: American Society for Microbiology (ASM); 2007.

7. Performance standards for antimicrobial susceptibility testing; Twentysixth informational supplement. CLSI document M100S. 26th ed. Wayne: Clinical and Laboratory Standards Institute; 2016.

8. Magiorakos A, Srinivasan A, Carey R, Carmeli Y, Falagas M, Giske C, et al. Multidrug-resistant, extensively drug-resistant and pandrug-resistant bacteria: an international expert proposal for interim standard definitions for acquired resistance. Clin Microbiol Infect. 2012;18:268-81. https://doi. org/10.1111/j.1469-0691.2011.03570.x. 
9. Sharma D, Vyas N, Sinha P, Mathur A. Non fermentative gram negative bacilli as nosocomial pathogens: identification and antibiotic sensitivity in clinical samples of indoor patients. Nepal J Med Sci. 2014;03:101-5. https://doi.org/10.3126/njms.v3i2.13452.

10. Malini A, Deepa E, Gokul B, Prasad S. Nonfermenting gram-negative bacilli infections in a tertiary care hospital in Kolar, Karnataka. J Lab Physicians. 2009;1:62-6. https://doi.org/10.4103/0974-2727.59701.

11. Bhargava D, Kar S, Saha M. Prevalence of non-fermentative gram negative bacilli infection in tertiary care hospital in Birgunj, Nepal. Int J Curr Microbiol Appl Sci. 2015;4:301-7.

12. Rahbar M, Mehragan $H$, Akbari N. Prevalence of drug resistance in nonfermenter gram-negative bacilli. Iran J Pathol. 2010;5:90-6.

13. Benachinmardi K, Padmavathy M, Malini J, Naveneeth B. Prevalence of non-fermenting Gram-negative bacilli and their in vitro susceptibility pattern at a tertiary care teaching hospital. J Sci Soc. 2014;41:162-6. https ://doi.org/10.4103/0974-5009.141204.

14. Nautiyal S, Jauhari S, Goel N, Mahawal B. Current trend of nonfermenting gram negative bacilli in a tertiary care hospital in Dehradun, Uttarakhand. Int J Adv Res. 2014;2:322-8.

15. Bhatnagar R, Kumar S, Bansal G, Mehra S. Identification and antimicrobial susceptibility pattern of clinical isolates of non-fermentative gram negative bacilli. Int J Pharma Res Health Sci. 2014;2:347-51.

16. Sah M, Mishra M, Ohora H, Kirikae T, Sherchand J, Rijal B, et al. Nosocomial bacterial infection and antimicrobial resistant pattern in a tertiary care hospital in Nepal. J Inst Med. 2014;36:38-48.

17. Jayapriya S, Lata S, Sumathi G. Nonfermentative gram negative bacillicharacterisation and antibiotic resistant pattern study from a tertiary care hospital. Indian J Basic Appl Med Res. 2014;3:227-32.

18. Shrestha S, Tada T, Shrestha B, Kirikae T, Rijal B, Pokhrel B, et al. Phenotypic characterization of multidrug-resistant Acinetobacter baumannii with special reference to metallo- $\beta$-lactamase production from the hospitalized patients in a tertiary care hospital in Nepal. J Inst Med. 2015;37:3-10.

19. Samawi M, Khan F, Eldeeb Y, Almaslamani M, Alkhal A, Ghadban W, et al. Acinetobacter infections among adult patients in Qatar: a 2-year hospitalbased study. Can J Infect Dis Med Microbiol. 2016;2016:1-5. https://doi. org/10.1155/2016/6873689.

20. Anil C, Shahid R. Antimicrobial susceptibility patterns of Pseudomonas aeruginosa clinical isolates at a tertiary care hospital in Kathmandu, Nepal. Asian J Pharm Clin Res. 2013;6:235-8.

21. Rit K, Nag F, Raj H, Maity P. Prevalence and susceptibility profiles of nonfermentative gram-negative bacilli infection in a tertiary care hospital of Eastern India. Indian J Clin Pract. 2013;24:451-5.

22. Dizbay M, Tunccan O, Sezer B, Aktas F, Arman D. Nosocomial Burkholderia cepacia infections in a Turkish university hospital: a five-year surveillance. J Infect Dev Ctries. 2009;3:273-7. https://doi.org/10.3855/jidc.124.

23. Lambiase A, Rossano F, Del Pezzo M, Raia V, Sepe A, de Gregorio F, et al. Sphingobacterium respiratory tract infection in patients with cystic fibrosis. BMC Res Notes. 2009. https://doi.org/10.1186/1756-0500-2-262.

24. Tronel H, Plesiat P, Ageron E, Grimont P. Bacteremia caused by a novel species of Sphingobacterium. Clin Microbiol Infect. 2003;9:1242-4. https:// doi.org/10.1111/j.1469-0691.2003.00801.x.

25. Eltahawy A, Khalaf R. Antibiotic resistance among Gram-negative nonfermentative bacteria at a teaching hospital in Saudi Arabia. J Chemother. 2001;13:260-4. https://doi.org/10.1179/joc.2001.13.3.260.
26. Erbay H, Yalcin AN, Serin S, Turgut H, Tomatir E, Cetin B, et al. Nosocomia infections in intensive care unit in a Turkish University Hospital: a 2-year survey. Intensive Care Med. 2003;29:1482-8. https://doi.org/10.1007/ s00134-003-1788-X

27. Mishra S, Shrestha R, Pokhrel B. The bad, the ugly and the demon: a tale of extensively drug-resistant, extended-spectrum-beta-lactamaseand metallo-beta-lactamase producing superbugs associated with nosocomial pneumonia. Asian Pac J Trop Dis. 2015;5:71-6. https://doi. org/10.1016/S2222-1808(14)60630-7.

28. Mishra S, Rijal B, Pokhrel B. Emerging threat of multidrug resistant bugs-Acinetobacter calcoaceticus baumannii complex and methicillin resistant Staphylococcus aureus. BMC Res Notes. 2013;6:1-6. https://doi. org/10.1186/1756-0500-6-98.

29. Xie D, Xiong W, Lai R, Liu L, Gan X, Wang X, et al. Ventilator-associated pneumonia in intensive care units in Hubei Province, China: a multicentre prospective cohort survey. J Hosp Infect. 2011;78:284-8. https://doi. org/10.1016/j.jhin.2011.03.009.

30. Fatima A, Naqvi S, Khaliq S, Perveen S, Jabeen S. Antimicrobial susceptibility pattern of clinical isolates of Pseudomonas aeruginosa isolated from patients of lower respiratory tract infections. Springerplus. 2012;1:70. https://doi.org/10.1186/2193-1801-1-70.

31. Ansari S, Dhital R, Shrestha S, Thapa S, Puri R, Chaudhary N, et al. Growing menace of antibacterial resistance in clinical isolates of Pseudomonas aeruginosa in Nepal : an insight of beta-lactamase production. Biomed Res Int. 2016. https://doi.org/10.1155/2016/6437208.

32. Behera B, Mathur P, Das A, Kapil A, Sharma V. An evaluation of four different phenotypic techniques for detection of metallo- $\beta$-lactamase producing Pseudomonas aeruginosa. Indian J Med Microbiol. 2008;26:233-7. https://doi.org/10.4103/0255-0857.39587.

33. Shrestha R, Dahal R, Mishra S, Parajuli K, Rijal B, Sherchand J, et al. Ventilator associated pneumonia in Tertiary Care Hospital, Maharajgunj, Kathmandu, Nepal. J Inst Med. 2013;35:21-8.

34. Mishra S, Acharya J, Kattel H, Koirala J, Rijal B, Pokhrel B. Metallo-betalactamase producing gram-negative bacterial isolates. J Nepal Health Res Counc. 2012;10:208-13.

35. Prakash V, Mishra P, Premi H, Apoorva W, Dhawan S, Kumar A. Increasing incidence of multidrug resistant Pseudomonas aeruginosa in inpatients of a tertiary care hospital. Int J Res Med Sci. 2014;2:1302-6. https://doi. org/10.5455/2320-6012.ijrms20141111.

36. Hassuna N, Mohamed A, Abo-Eleuoon S, Rizk H. High prevalence of multidrug resistant Pseudomonas aeruginosa recovered from infected burn wounds in children. Arch Clin Microbiol. 2015;6:1-7.

37. Sattler C, Mason E, Kaplan S. Nonrespiratory Stenotrophomonas maltophilia infection at a children's hospital. Clin Infect Dis. 2000;31:1321-30. https://doi.org/10.1086/317473.

\section{Publisher's Note}

Springer Nature remains neutral with regard to jurisdictional claims in published maps and institutional affiliations.

Ready to submit your research? Choose BMC and benefit from:

- fast, convenient online submission

- thorough peer review by experienced researchers in your field

- rapid publication on acceptance

- support for research data, including large and complex data types

- gold Open Access which fosters wider collaboration and increased citations

- maximum visibility for your research: over $100 \mathrm{M}$ website views per year

At BMC, research is always in progress.

Learn more biomedcentral.com/submissions 